University of Warwick institutional repository: http://go.warwick.ac.uk/wrap

This paper is made available online in accordance with publisher policies.

Please scroll down to view the document itself. Please refer to the repository record for this item and our policy information available from the repository home page for further information.

To see the final version of this paper please visit the publisher's website. Access to the published version may require a subscription.

Author(s): Robinson, Elizabeth.J., Haigh, S.N. \& Nurmsoo, E.

Article Title: Children's working understanding of knowledge sources:

Confidence in knowledge gained from testimony

Year of publication: 2008

Link to published version: doi:10.1016/j.cogdev.2007.05.001 
Running head: Working understanding of knowledge sources.

Children's Working Understanding of Knowledge Sources:

Confidence in Knowledge Gained from Testimony

\author{
E.J. Robinson, \\ Warwick University, U.K.
}

S.N. Haigh,

Keele University, U.K.

E. Nurmsoo

Warwick University, U.K.

Cognitive Development, in press, May 2007

Author note. The research was supported by a grant from the Economic and Social Research Council, U.K. (RES000220825).

Correspondence concerning this article should be addressed to E.J. Robinson, Department of Psychology, Warwick University, Coventry CV4 7AL, U.K.

Keywords: source monitoring; testimony; knowledge; uncertainty 
Working understanding of knowledge sources

\begin{abstract}
In three experiments children aged between 3 and 5 years $(\mathrm{N}=38 ; 52 ; 94$; mean ages $3 ; 7$ to $5 ; 2$ ) indicated their confidence in their knowledge of the identity of a hidden toy. With the exception of some 3-year-olds, children revealed working understanding of their knowledge source by showing high confidence when they had seen or felt the toy, and lower confidence when they had been told its identity by an apparently well-informed speaker, especially when the speaker subsequently doubted the adequacy of his access to the toy. After a 2-minute delay, 3-to 4- year olds, unlike 4- to 5-year-olds, failed to see the implications of the speaker's doubt about his access.
\end{abstract}


Working understanding of knowledge sources

\section{Children's Working Understanding of Knowledge Sources: Confidence in Knowledge Gained from Testimony}

The ability to recall or infer how we know something is crucially important for assessing the accuracy of our knowledge (Johnson, Hashtroudi \& Linsday, 1993). Suppose a companion on a country walk reports spotting an unusual bird that I failed to notice. I have no reason to doubt her, and so I believe that this particular bird was indeed in the area. However, that evening my companion mentions that she was not wearing her glasses on the walk. If I recollect that she was the source of my belief about the bird's presence, I might now be less sure of its truth: I thought she had seen the bird adequately to identify it and differentiate it from a more common variety, but now I find that she had not. In contrast, if I do not recollect how my belief was acquired, I will draw no such implication from her comment about the missing glasses. I will continue to treat my belief as factually true. Importantly, this kind of source-identification and evaluation allows adults to keep a check on the likely truth of their knowledge even in the absence of contradicting information. Note that in this example I had no independent information that the bird was not present, but nevertheless I had good grounds for reducing my confidence in my belief that it was.

The need to engage in such source identification and evaluation arises early in childhood. As children's mastery of language increases, they need skills to assess the likely truth of what they are told in order to benefit fully from other people's experience of the world. This holds not just at the time of originally hearing an utterance, but also, as in the example above, subsequently, once the information conveyed has become part of their own knowledge base. Without such skills, children will be at risk of believing what is false or disbelieving what is true. 
Working understanding of knowledge sources

In the research reported below we examined how 3- to 5- year-old children behaved in circumstances similar to the example above. A speaker appeared to have seen a hidden toy before telling the child its color, or to have felt before telling the child whether it was hard or soft. After the child believed what she was told, the speaker doubted that he had felt or looked properly. Would children realise that his doubt had specific implications for the likely truth of their belief, even though they had no independent evidence that their belief might be false?

Previous research does not tell us the answer, nor even give clear indications about what to expect. We know a good deal about young children's decisions about whether or not to believe what they are told at the time they first hear it, but very little about how this knowledge is subsequently treated. For example, research on word learning shows that many 4-year-olds, and under some conditions 3-year-olds, are sensitive to a speaker's past mislabelling and to a speaker's assertion of her own ignorance when they decide whether or not to believe that speaker's naming of a new unfamiliar object (e.g. Birch \& Bloom, 2002; Koenig, Clement \& Harris, 2004; Koenig \& Harris, 2005; Sabbagh \& Baldwin, 2001). Similarly, children's decisions to believe what they are told about features of the physical world reveal early competence under some conditions. Both 3- and 4-year-olds show sensitivity to a speaker's perceptual access to a hidden toy when they decide whether or not to believe that speaker's assertion about its identity (Robinson \& Whitcombe, 2003; Whitcombe \& Robinson, 2000). For example, children were asked to guess the color of a hidden toy after having only felt it (e.g., "It's the red one"), and the speaker then gave a contradicting suggestion (e.g., "It's the blue one"). Children believed this contradicting suggestion when the speaker was better informed than they were, having seen the toy. In contrast, they were equally likely to believe or disbelieve the 
Working understanding of knowledge sources

suggestion when both they and the speaker had only felt the toy. These studies show that children are sensitive to a speaker's current perceptual access, as well as her past history, when deciding whether to believe what they are told.

We do not know, however, how children subsequently treat beliefs acquired from others. Do they retain any information that those beliefs were gained indirectly rather than directly? Between the ages of 3 and 5 years there are substantial improvements in children's ability to report the source of knowledge recently acquired (e.g. Gopnik \& Graf, 1988; O’Neill \& Gopnik, 1991; Wimmer, Hogrefe \& Perner, 1988). However, explicit source reports might be neither necessary nor sufficient for children to show appropriate uncertainty when a speaker's informedness is called into question. For example, children who can accurately report "I know because you told me," may not realise the implications of the speaker being less well informed than originally appeared to be the case. On the other hand, children who cannot report explicitly that the speaker was the source of their knowledge might nevertheless demonstrate working understanding of their knowledge source.

In the Experiments reported below, children found out which one of a pair of toys was hidden in a tunnel, either from their own direct experience or from a cooperative and apparently well-informed Experimenter. In both cases the Experimenter subsequently expressed doubts about the adequacy of his own access to the hidden toy. This doubt had implications for the truth of the child's knowledge only when it had been gained from him: Children should now be unsure about the target toy's identity, on the basis of reasoning "I believed what you said because you appeared to be well-informed; if after all you were not well-informed, what you said might or might not be true." In contrast, when knowledge was gained by seeing or feeling the toy directly, children should still be certain of the hidden toy's identity 
Working understanding of knowledge sources

even after the Experimenter expressed doubt about his own access. In Experiments 1 and 2 we found out whether or not children differentiated between these two conditions.

If they did differentiate, and were more uncertain when they had relied on the Experimenter for their knowledge of the toy's identity, there could be two explanations. The strong explanation is that they reasoned in the way specified above, seeing the specific implications of the speaker's doubt about his access. This would imply that they could not only identify the source of their own knowledge (being told by the Experimenter $v s$ feeling or seeing for themselves), but also identified the Experimenter's source of knowledge when they had relied on him, and saw the connection between that source of knowledge being less well accessed than they thought, and the reliability of their own knowledge.

On the other hand there could be a weaker explanation for differentiation between conditions (that is, if children are more uncertain when they relied on the Experimenter for their knowledge of the toy's identity than when they found out for themselves). Knowledge gained indirectly from another person might by default be held more tentatively than knowledge gained directly. Perner (1991) argues that from their earliest days, children must be more sceptical of what they are told about the world than of their own direct experience, otherwise their knowledge base would be unstable. An automatic process that is sensitive to whether information is gained directly or from a speaker's utterance could be considered to involve some kind of source monitoring on a rudimentary level, but would be less sophisticated than the source identification and evaluation involved if implications are drawn from the speaker's doubt about his own access. 
Working understanding of knowledge sources

In Experiment 3 we tested these weak and strong explanations for children's uncertainty in knowledge gained from a speaker, either or both of which could be correct. For example, children might by default be uncertain of knowledge gained indirectly, but also engage in the complex analysis outlined under the strong explanation. Our main interest was in establishing whether the strong explanation held, but we were also interested in whether or not there was evidence for the weak explanation.

\section{Experiment 1}

We aimed to find out whether children aged 3 and 4 years were less confident in knowledge gained from an apparently well-informed speaker who subsequently doubted his access, than in knowledge gained directly by seeing or feeling, without yet committing ourselves to the strong or the weak explanation. We also examined how children's relative confidence in knowledge gained directly or indirectly related to their ability to report explicitly when their knowledge was gained from the Experimenter. As discussed in the introduction, children who can report explicitly that the Experimenter was the source of their knowledge might nevertheless fail to see the implications of his expressed doubt about his access. On the other hand, children who cannot offer explicit source reports might reveal a working understanding sufficient to realise the implications.

\section{Method.}

Participants. The final sample consisted of 38 children (19 girls): 25 4- yearolds from reception classes, in their first year of formal schooling (range 4;0 to 5;0, mean 4;6 ) and 13 3- year-olds from nursery classes (range 3;2 to 4;0, mean 3;7). All children in this and subsequent experiments attended schools serving predominantly white working and middle class areas of mid- and northern U.K. An additional 6 
Working understanding of knowledge sources

children were excluded, 2 of whom replied "Yes" to all questions on the 4

experimental trials and 4 of whom failed to repeat the Experimenter's well informed suggestion on at least one of the tell trials (and so, as explained below, were not asked the subsequent doubt or source questions).

Materials. We used a tunnel $(15 \times 15 \times 35 \mathrm{~cm})$ open at both ends, with a window in one side. The window and both ends of the tunnel had opaque curtains that could be lifted to allow viewing through the window, or an arm to enter either end. We used eight pairs of toys (for example stylised cats, lions, bears and frogs). One toy in each pair felt soft and the other felt hard, but the two looked the same, so children could not identify which toy it was just by looking. A glove puppet, Mole, operated by the Experimenter using a distinctive voice, asked some of the test questions. A bag was used to contain toys while they were concealed in the tunnel.

Design and Procedure. In a within subjects design, children received 2 warmup trials (described at the end of the procedure section) followed by 4 experimental trials. The experimental trials comprised two source trials that tested children's explicit source identification, and two doubt trials that assessed children's ability to identify and evaluate knowledge sources in working understanding. On one doubt trial and one source trial children gained knowledge from the apparently well-informed Experimenter (tell trials, children believed what they were told) and on the others, they gained knowledge from their own direct experience (direct trials).

The procedure on doubt trials follows (see Table 1). Stages (i) to (iv) served only to lead children to gain knowledge either directly or from the Experimenter. This part of the procedure was heavily based on previous work (Robinson \& Whitcombe, 2003; Whitcombe \& Robinson, 2000) but further checks were made in a preliminary 
Working understanding of knowledge sources

study using this specific procedure ${ }^{1}$. The novel part of the procedure, where the Experimenter expressed doubt about his access, is at stage (v):

(i) The child was introduced to a pair of toys and agreed on their properties. Both toys were placed in the bag, shaken, and one toy was slipped from the bag into the tunnel apparently without anyone knowing which one. In fact the Experimenter (SH) discreetly identified the toy.

(ii) The Experimenter said, "Now I'm going to look / feel inside and tell you which toy I think is inside." He then either looked at or felt the toy in the tunnel, and identified it correctly, for example "The soft cat."

(iii) The child was then invited to look at (when the Experimenter had felt) or feel (when the Experimenter had looked) the toy inside the tunnel.

(iv) The puppet Mole then asked the child an identity question, "Which one is inside please?" On direct trials, the child had felt the toy and could answer this identity question correctly on the basis of her own direct experience. On tell trials, the child had seen the toy but could answer the identity question correctly by relying on the Experimenter's suggestion, since he had felt it. If the child's identity judgment on a tell trial was not in line with the Experimenter's suggestion, the trial was terminated (see participants section above for exclusions). The great majority of children repeated the Experimenter's suggestion and continued:

(v) The Experimenter doubted the reliability of his access, saying, "I'm not sure I looked / felt inside properly" followed by the doubt question: "Could it be the [other toy]?"

(vi) After the child's response, the Child and Experimenter removed the toy from the tunnel to check its identity. Children always found out that the Experimenter had in fact given the correct identity judgment, so there was no accumulating 
Working understanding of knowledge sources

evidence of unreliability when the Experimenter had appeared to be well-informed, despite his assertions of doubt.

The procedure on source trials began in a similar way (see Table 1): The Experimenter either saw or felt the toy and told the child which one he thought it was, but on source trials when the Experimenter saw the toy he gave the wrong identity judgment, so that the Experimenter was not a correct source of the child's knowledge. The child then felt the toy and could identify it correctly. Mole then asked the identity question as on doubt trials. Stage (v) of the procedure was different: Instead of expressing doubt, the Experimenter assessed children's ability to report the source of their knowledge: "So, you found out it was the [hard / soft] one. Did you find out it was the hard / soft one because I told you, yes or no?" (the source question). This two sentence structure allowed children to follow their inclination to assent to the content of their belief (it's the hard one) but then to focus on the question about its source (did you find out because...). As on doubt trials, source trials ended with child and Experimenter checking the toy's identity, and this time the child discovered that the Experimenter had been wrong when he had only seen the toy, so there was no accumulation of evidence that the Experimenter was always correct despite being poorly informed.

The classic source question used in the published literature is "How do you know ...?" However, to use this question here might make an unfair comparison with the question "Could it be the [other toy]?" which demands a response of only "Yes" or "No". We therefore used a source question that demanded only "Yes" or "No" in response.

To encourage children to attend to the Experimenter's mode of obtaining knowledge (by seeing or feeling the toy) and to see its relevance, two warm-up trials 
Working understanding of knowledge sources

(one direct and one tell) at the beginning of the game followed a similar format up to stage (iv) but included explanatory comments. On the direct trial the Experimenter (poorly informed) made the incorrect suggestion, and pointed out at the end of the trial that he had been wrong. On the tell trial the Experimenter (well-informed) gave the correct suggestion and pointed out at the end of the trial that he had been right. Warm-up trials ended after children had made their identity judgment and checked its accuracy by taking the target toy out of the tunnel. The order of the 4 experimental trials was counterbalanced and cycled between children, as were forced choice responses of 'yes' and 'no' for the source and belief revision questions. Results and Discussion.

Responses to doubt question. The doubt question "Could it be the [other toy]?" tested children's confidence in the toy's identity after the speaker doubted his own perceptual access. A response of "Yes" (it could be the other toy) was taken to indicate lack of confidence in the toy's identity, and "No" to indicate confidence. If children realised the implications of the speaker's doubt about his own perceptual access, they should be less certain on the tell trial (when children were told the toy's identity by the Experimenter), than on the direct trial (children's knowledge came from their own direct experience).

On the direct trial children were confident in the toy's identity: 37 out of 38 (97\%) children responded "No" (it could not be the other toy). One 3-year-old child responded "Yes." On the tell trial, children were less certain: Only 16 children out of $38(42 \%)$ responded "No," while $22(58 \%)$ responded "Yes", accepting that it could be the other toy. Breaking the sample by age revealed that only the 4-year-olds were significantly more likely to say "No" on the direct than on the tell trial: Amongst 4year-olds who responded differently in the two trials, 17 children said "No" on the 
Working understanding of knowledge sources

direct trial only and "Yes" on the tell trial, whereas no child showed the opposite pattern of responding: McNemar $\chi^{2}(\mathrm{~N}=25) p<.001$. The 3-year-olds in contrast showed no significant differentiation between direct and tell trials: The equivalent frequencies were 4 and 0 . The 3-year-olds who said "No" on the direct trial were more likely than the 4-year-olds to also say "No" on the tell trial: 8 out of 12 3-yearolds did so, compared with 8 out of 254 -year-olds, $\chi^{2}(\mathrm{df}=1, \mathrm{~N}=37)=3.97, p=$ .046. These 3-year-olds showed over-confidence in knowledge gained from the Experimenter.

Responses to source question. Children were asked, "Did you find out it was the [hard/soft] one because I told you?" The correct pattern of responding to the source question was "No" on the direct trial, when children had felt the object for themselves, and "Yes" (I do know because you told me) on the tell trial. Eighteen of the 38 children (47\%) showed this pattern (1 out of 13 3-year-olds and 17 out of 254 year-olds). Most of the remaining responses were "Yes" on both trials (11 3-year-olds and 8 4-year-olds): A "Yes" bias is not unexpected from children who simply did not know how they knew which toy was in the tunnel.

Relationship between responses to doubt and source questions. For each question, children were scored as passing when they said "No" (it couldn't be the other one OR you didn't tell me) on the direct trial (when they had found out for themselves) and "Yes" on the tell trial (when they had relied on the Experimenter). All other response patterns were scored as failures. There was a significant correlation for the sample as a whole between performance on the two tasks: 15 children passed both, 13 failed both, 6 passed only doubt question and 4 passed only the source question: $\chi^{2}(\mathrm{df}=1, \mathrm{~N}=38)=8.62, p=.003$. Breaking down by age, the equivalent frequencies for the 4 year-olds were $14 ; 5 ; 3 ; 3: \chi^{2}(\mathrm{df}=1, \mathrm{~N}=25)=5.029, p=.025$. 
Working understanding of knowledge sources

Most of the 3-year-olds failed both tasks, making statistical analysis unreliable. The equivalent frequencies were $1 ; 8 ; 3 ; 1$.

Despite the significant association between children's ability to make explicit whether they had gained their knowledge from the Experimenter, and their showing the appropriate pattern of confidence in knowledge gained directly and indirectly, there was some indication that children performed better at doubt than at source judgments. Children who failed to show the correct pattern of "Yes" and "No" judgments on the source questions $(\mathrm{N}=19)$, nevertheless differentiated as a group between direct and tell trials in their answers to the doubt question: 6 children correctly said "No" (it could not be the other one) on the direct trial and "Yes" (it could be the other one) on the tell trial, whereas no child showed the opposite pattern of responding: McNemar $\chi^{2}(\mathrm{~N}=19) p=.03$. That is, correct explicit source reports were not necessary for children to show relative uncertainty in knowledge gained on tell trials. In contrast, children who failed to show the correct pattern of "Yes" and "No" judgments in answer to the doubt questions $(\mathrm{N}=17)$, showed no differentiation between direct and tell trials in their answers to the source question: 3 correctly said "Yes" on the tell trial only, compared with 0 who incorrectly said "Yes" on the direct trial only. That is, there was no sign that children could report their knowledge source explicitly yet fail to be less certain of knowledge gained on tell trials than on direct trials.

Taking all the results together, the youngest children were over-confident in knowledge gained from the Experimenter, frequently denying that it could be the other toy in the tunnel, and showing no differentiation between tell and direct trials in their responses to the doubt question. Some children who did differentiate between tell and direct trials in their responses to the doubt question, nevertheless revealed no 
Working understanding of knowledge sources

explicit understanding of their knowledge sources. Finally, some children both differentiated between direct and tell trials in response to the doubt question, and also showed explicit understanding in response to the source questions. The current data do not allow us to argue that these three response patterns form a developmental sequence, but it is plausible that they do. A similar sequence has been identified in work on implicit understanding of false belief: Some 3-year-olds who fail a standard false belief test that demands verbally explicit understanding, show eye movements suggesting implicit understanding, but younger children's eye movements do not (Clements \& Perner, 1994; Ruffman, Garnham, Import \& Connolly, 2001).

The results show the basic effect of interest: Less certainty in knowledge gained from the Experimenter on tell trials, than in knowledge gained directly. This is the minimum effect needed to argue that children realised that the Experimenter's doubt about his access had implications for the likely truth of their belief only when they had relied on what the Experimenter told them. However as pointed out in the introduction we cannot yet be sure whether this strong explanation is justified. Before finding that out in Experiment 3, in Experiment 2 we checked on the robustness of the basic effect by measuring children's confidence in a different way.

Experiment 2

In Experiment 1, after the Experimenter had expressed doubt about his access, children could express uncertainty about the identity of the hidden toy by answering 'Yes' to 'Could it be the other one?' In Experiment 2, in contrast, we gave children the opportunity to change their mind about which toy was hidden. Would children more frequently change their mind on tell trials, when they relied on the speaker, than on direct trials, when they did not? If so, this would be consistent with their 
Working understanding of knowledge sources

understanding that speaker's expression of doubt about his access had implications only when they had relied on him.

We also included a condition in which a puppet, rather than the Experimenter, saw or felt the hidden toy and then expressed doubt about his access. This checked that children attended to the speaker role when answering the doubt question, rather than just to the Experimenter as an authoritative adult.

\section{Method.}

Participants. The final sample consisted of 48 children (24 girls). Due to one head teacher's concern to maintain children's privacy, birthdates were not provided for participants at one nursery (17 children between the ages of 3;9 and 4;9). The mean age of the participants with reported birthdates was $4 ; 1$ (range $3 ; 3-4 ; 9$ ). Only two children were under the age of $3 ; 7$, the mean age of the nursery sample of Experiment 1. An additional 12 children were excluded, 2 for experimenter error, 1 for language difficulties, and 9 for failing to repeat the speaker's well informed suggestion on at least two of the tell trials.

Materials. These were as in Experiment 1, except that the Mole puppet was replaced by a Monkey who, unlike Mole, had arms long enough to feel a toy hidden inside the tunnel.

Procedure. In a mixed design, children entered either the Experimenter or the Monkey condition alternately, and had both direct trials (they believed their own experience of the hidden toy) and tell trials (they believed what the well informed Experimenter told them). In both conditions the sequence of events was similar to that on the doubt trials in Experiment 1. In the Experimenter condition, the Experimenter (EN) was the speaker and the puppet hid the toys and asked the questions, whereas in the Monkey condition, the roles were reversed. 
Working understanding of knowledge sources

Two warm-up trials preceded the experimental trials. On the tell warm-up trial, the speaker (puppet or experimenter, depending on condition) felt the toy in the tunnel and correctly reported the toy's identity, before the child looked and made her guess. On the direct warm-up trial, the speaker looked, made an incorrect identification, and the child felt and made her guess. On warm-up trials the speaker never expressed doubt, and the toy was always retrieved from the tunnel for final identification. These trials were included to familiarize the participant with the basic procedure. After these two warm-up trials, children received four experimental trials. Experimental trials followed the procedure used in Experiment 1: One of a pair of toys was hidden in the tunnel. The speaker either felt the object in the tunnel (tell trials) or looked at the object in the tunnel (direct trials) before correctly identifying the toy. The child then had a turn, looking at the object if the speaker had felt, or feeling the object if the speaker had looked. The child was then asked by whoever was not the speaker, "So which one is it, the hard one or the soft one?" After the child made her guess, the speaker expressed doubt ("Now that I think of it, I'm not so sure I felt [looked] properly. I wonder if it could be the hard [soft] one!") and the child was asked again by the non-speaker, "Well, what do you think - hard or soft?" This repeated identity question replaced the doubt question of Experiment 1.

In both conditions, the first two experimental trials consisted of one tell and one direct trial in counterbalanced order, followed by a filler trial, and a second pair of tell and direct trials. On the filler trial the speaker had uninformative access and guessed the identity of the toy incorrectly, before the child had informative access and made her guess. The speaker did not express doubt. This trial was included in order to decrease the likelihood that participants would become suspicious that the speaker always guessed correctly even when poorly informed. 
Working understanding of knowledge sources

\section{Results and Discussion}

After the speaker expressed doubt, children could either repeat their former answer to the identity question, or change their mind. A change of mind suggests that the child lacked confidence in the original judgment. There was no significant difference between the Experimenter and Monkey conditions in the frequency of changing (see Table 2), so the results were collapsed across speaker.

On direct trials, children had informative access, feeling the object in the tunnel for themselves. As expected, children switched responses on direct trials at a frequency significantly below chance $\left(\chi^{2}(\mathrm{df}=2, \mathrm{~N}=48)=81.5 p<.001\right)$. On tell trials, however, children had to rely on the speaker's utterance to identify the object. On these trials, children switched their responses at a frequency no different from chance. Children were significantly more likely to switch on tell trials than on direct trials (Wilcoxon signed ranks test: $z(N=48)=-3.695, p<.001)$. As a group, the children behaved as though they were less confident in knowledge gained indirectly from a speaker, than in knowledge gained directly.

\section{Experiment 3}

In the final Experiment we examined the basis of children's greater uncertainty about the toy's identity when they had relied on the speaker. We tested the strong and weak explanations specified in the introduction. According to the strong explanation, children reasoned in line with "I believed what you said because you appeared to be well-informed; if after all you were not well-informed, what you said might or might not be true." According to the weak explanation, they are by default less confident in knowledge gained indirectly from others, than in knowledge gained directly: They would be relatively uncertain in the toy's identity on tell trials even if no doubt was cast on the adequacy of the speaker's access to the toy. 
Working understanding of knowledge sources

To find out whether the strong explanation holds, we need a condition in which children find out the toy's identity from a speaker, but no doubt is subsequently expressed about the adequacy of the speaker's access to the toy. If children are just as unsure of the toy's identity whether or not the speaker's access is called into question, then we cannot accept the strong explanation. In Experiment 3 we introduced such a condition. The observing puppet Mole doubted the identity of the hidden toy without doubting the Experimenter's access and without giving any other reason. We compared children's responses to the doubt question on tell trials (when children's knowledge of the toy's identity came from what they were told) under this new condition, and under the original condition used previously, when the Experimenter's doubted his access. If children more frequently accepted that it could be the other toy following the Experimenter's doubt about his access rather than Mole's doubt about the toy's identity, this would be consistent with the strong explanation.

The Mole condition also allowed us to test whether the weak explanation held, by comparing direct trials (children knew the toy's identity from their own experience) $v s$ tell trials (children knew from being told). If children were less confident when Mole doubted the toy's identity on tell trials than on direct trials, this would suggest that children by default hold knowledge gained from utterances tentatively compared with knowledge gained directly, even if there is no particular reason to doubt the speaker's reliability.

We could find either or both of these effects. For example, children might by default be uncertain about knowledge gained from a speaker (evidenced by greater uncertainty on tell than direct trials when Mole doubts the toy's identity), but in addition see the specific implications of the speaker's doubt about his access 
Working understanding of knowledge sources

(evidenced by greater uncertainty on tell trials when the Experimenter doubts his access than when Mole doubts the toy's identity).

We also included trials with a brief delay between the children identifying the hidden toy and the doubt question. We were interested in whether children suffered a loss of source specifying information over this short delay (e.g. Pillow \& Anderson, 2006). If they did, then any differentiation on tell trials between Mole and

Experimenter doubt conditions might be lost, and children might also lose differentiation between direct and tell trials. Finally, with the aim of finding ceiling or near-ceiling performance, we included a sample of older children aged between 4 and 5 years.

In Experiment 3 we used the doubt question used in Experiment 1. In Experiment 2, the repeated identity question forced children to commit themselves to which toy was in the tunnel, when strictly they could not know once the speaker's information access was called into question. The rational answer was, “I don't know," a response young children are unlikely to give. In contrast, the doubt question ("Could it be the other one?") allowed children to express genuine uncertainty: "Yes, it could be the other toy."

Method.

Participants. We report data from 94 children. Fifty-five children were from nursery classes (35 girls, range 3;4 to 4;9, mean 4;2). Thirty-nine children were in a reception class in their first year of formal schooling, (23 girls, range 4;8 to 5;7, mean $5 ; 2)$. An additional 6 children were not included because they failed to repeat the Experimenter's well informed suggestion on at least one of the tell trials and so were not asked the subsequent doubt questions. 
Working understanding of knowledge sources

Materials. We used pairs of toys that differed in color only. For the trials involving a delay between the child's identity judgment and the belief revision question, we prepared outline drawings of the toy pairs for children to color in.

Design and Procedure. In a mixed design, children entered either the Experimenter doubt or the Mole doubt condition. Each child had one direct and one tell trial with no delay between the identity judgment and the doubt question, as in Experiments 1 and 2. Each child also had one direct and one tell trial with a delay of approximately 2 minutes between the child giving her identity judgment and the doubt question.

The procedure followed stages (i) to (iv) as described in Experiment 1 except that seeing rather than feeling was informative. On the delay trials, after the child had made her identity judgment, the Experimenter moved the tunnel out of the child's reach leaving the toy hidden inside, and presented the child with outline drawings of the toy pair in question and appropriately colored crayons. After approximately 2 minutes when children had finished their coloring or were at a suitable point to be interrupted, they were asked to recall which toy they had said was inside the tunnel. Only children who responded correctly continued with the remaining procedure on that trial.

Children then entered Experimenter doubt or Mole doubt conditions alternately. For children in the Mole doubt condition, Mole said, for example, "I'm not sure it's the (red cat)" followed by the doubt question: "Could it be the (blue cat)?" For the 3- to 4-year-olds in the Experimenter doubt condition, the Experimenter doubted his access as at stage (v) of the procedure in Experiment 1, and then asked the doubt question. In pilot work, some 4- to 5-year-olds responded to the Experimenter's doubt that he might not have looked or felt properly by reassuring him 
Working understanding of knowledge sources

that such an error was very unlikely. Therefore for the 4 to 5 -year-olds only, in the Experimenter doubt condition the Experimenter used the same wording as Mole, doubting the toy's identity without giving a reason. This modification resulted in the older children receiving less clear-cut clues to help their source monitoring, as compared with the younger ones, and so if anything we risked under-estimating their abilities.

We also included 2 filler trials to ensure that the Experimenter was not always correct. Again, comments made by children in pilot work suggested the need for different filler trials for two age groups. Children of both ages experienced the Experimenter giving an incorrect identity judgment when he was poorly informed and the older children additionally experienced themselves being wrong when poorly informed. For the 3- to 4-year-olds, the child guessed the toy's identity correctly and the Experimenter guessed incorrectly. For 4- to 5-year-olds both the child and Experimenter guessed the toy's identity incorrectly. The Experimenter managed the content of the tunnel to ensure this outcome. The order of the 4 experimental trials (2 direct and 2 tell, 2 delay and 2 no delay) was completely counterbalanced between children. The two filler trials always appeared at the second and forth trial positions. Results.

Frequencies of "No" judgments in response to the doubt question appear in Table 3. Recall that on tell trials children's knowledge of the toy's identity came from what they were told, and on direct trials it came from their own direct experience. We were interested in testing the strong explanation: Did children see the specific implications of the speaker's doubt about his access (evidenced by greater uncertainty on tell trials when the Experimenter doubted his access than when Mole doubted the toy's identity); and the weak explanation: Are children by default uncertain about 
Working understanding of knowledge sources

knowledge gained from a speaker (evidenced by greater uncertainty on tell than direct trials when Mole doubted the toy's identity).

Responses to doubt questions with no delay. As in the previous experiments, a response of "No" to the question "Could it be the [other toy]?" was interpreted as indicating certainty in the identity of the hidden toy. The results shown in Table 3 suggest that results are in line with both the weak and the strong explanations.

To test the weak explanation, we compared the frequency of "No" responses to the doubt question on direct trials and tell trials in the Mole doubt condition. McNemar tests showed there was a near significantly or significantly lower incidence of "No" judgments on tell than on direct trials in the Mole doubt condition: 3- to 4year-olds $[\mathrm{N}=26] p=.07$; 4- to 5-year-olds $(\mathrm{N}=18) p=.016$. That is, for the older children at least, there appeared to be a default lack of confidence in knowledge gained from the Experimenter. As expected, we also found the same effect in the Experimenter doubt condition: 3- to 4-year-olds $(\mathrm{N}=29) p<.001$; 4- to 5-year-olds no calculation due to $100 \%$ on direct trials. This replicates the results Experiment 1.

Consistent with the strong explanation, on tell no delay trials there was a lower incidence of "No" judgments in the Experimenter doubt than in the Mole doubt condition: 3 - to 4 - year-olds $\chi^{2}(\mathrm{df}=1, \mathrm{~N}=55)=6.43, p=.011 ; 4$ - to 5-year-olds $\chi^{2}$ $\mathrm{df}=1,(\mathrm{~N}=39)=4.17, p=.041$. That is, on tell trials when the Experimenter doubted his own access, children were less certain of the identity of the toy than when Mole doubted the toy's identity for no good reason. Importantly, children differentiated between the two doubt conditions (Mole vs Experimenter) on tell trials only. Had they also differentiated on direct trials, this would have suggested that for some reason children were simply more likely to acquiesce to the doubt question when it was asked by the Experimenter rather than Mole. The pattern of judgments 
Working understanding of knowledge sources

obtained suggests that children realised that they had believed the Experimenter because he appeared to be well informed; if he was not, their belief about the toy's identity might not be true.

Responses to doubt questions with delay. After the two minute delay, it could have been that information about sources of the information was lost, and that as a consequence children became overly confident on tell trials, just as the sample of 3year-olds in Experiment 1 were on no delay trials. However, as shown below and in Table 3, children in both age groups held their belief about the toy's identity more tentatively on tell trials than on direct trials.

The 4- to 5-year-olds continued to differentiate between direct and tell trials in the Experimenter doubt condition, as in in the no delay conditions in Experiments 1 and 3: They showed a significantly lower incidence of "No" judgments on tell than on direct trials $(\mathrm{N}=20) p=.001$. They also showed the additional pattern of responses necessary to support the strong explanation for this uncertainty: They showed a lower incidence of "No" judgments on tell trials in the Experimenter doubt than in the Mole doubt condition: $\chi^{2}(\mathrm{df}=1, \mathrm{~N}=39)=5.66, p=.017$. However, support for the weak explanation was not found: There was no significant difference in the Mole doubt condition in the frequency of "No" judgments on direct and tell trials: $(\mathrm{N}=15) p=$ .13.

The 3- to 4-year-olds also showed a significantly lower incidence of "No" judgments on tell than on direct trials in the Experimenter doubt condition: $(\mathrm{N}=26)$ $p=.039$. However, unlike the older children, the 3- to 4-year-olds showed no sign of differentiation between Experimenter doubt and Mole doubt conditions on tell trials, with $42 \%$ "No" responses on the former, and $43 \%$ on the latter (see Table 3 ). Hence support for the strong explanation was lost. On the other hand, the 3- to 4-year-olds 
Working understanding of knowledge sources

did show support for the weak explanation for uncertainty in knowledge gained from the Experimenter: In the Mole doubt condition were there significantly fewer "No" judgments on tell trials than on direct trials: $(\mathrm{N}=21) p=.039$.

The important findings from this Experiment are: (i) On no delay trials, children were less confident about knowledge gained indirectly from utterances than about knowledge gained directly, even when no doubt was expressed about the adequacy of the speaker's access to the hidden toy (Mole doubt condition). This is in line with the weak explanation for uncertainty about knowledge gained from others; (ii) Over and above this uncertainty, on no delay trials children realised the specific implications of the speaker's doubt about his access, as if reasoning “...if you were not well informed, my belief could be false", in line with the strong explanation; (iii) After a delay, there was some loss of source information amongst the younger children. Although they remained less certain in knowledge gained indirectly, they failed to reveal understanding of the specific implications of the speaker's doubt about his access to the toy.

\section{General Discussion and Conclusions}

As children's increasing mastery of language allows them to learn from other people's knowledge and experience, they need skills to evaluate the likely truth of what they are told. The findings reported here add to the evidence that many 3-and 4year-olds are well equipped to benefit from what other people tell them, and can guard against the risks associated with learning from others. The findings also add to our knowledge of children's source monitoring skills, suggesting that working understanding of sources of knowledge can help children evaluate the likely truth of their knowledge, even if they cannot yet report explicitly its source. 
Working understanding of knowledge sources

We already knew, and we confirmed in the Experiments reported here, that 3and 4-year-old children can take into account speakers' mode of information access when deciding whether or not to believe what is said. For example, they believed what they were told about a hidden toy's color only when the speaker had seen it and not when he or she had felt it. The new findings concern the weight that children subsequently give to this knowledge. When doubts were expressed about the speaker's access, 3- to 4-year-olds (mean ages 4;1 and 4;2 in Experiments 1 and 2) and 4- to 5-year olds (Experiment 3) continued to hold the knowledge gained with appropriate caution, at least in the short term. For example they often accepted that the toy's color could have been different when their knowledge came from the speaker, but rarely did so when they had seen the toy for themselves.

Experiment 3 showed that this uncertainty in knowledge gained from others had two distinct bases. First, we found evidence of a default lack of confidence in knowledge gained indirectly, possibly based on an automatic process involving source monitoring on an implicit level. Even when no doubt was expressed about the speaker's access to the toy, but instead Mole expressed doubt about the target toy's identity without giving a reason, children were less confident about the toy's identity when their knowledge came from the Experimenter than when they had found out for themselves. We describe this as the 'weak' explanation for uncertainty, because it could be based simply on automatic processes (Perner, 1991), but this is not to imply it is uninteresting. It could have been that having decided to believe what they were told, children then held knowledge so gained with just as much confidence as if it had been gained directly unless they had good reason to question it, as they did when the speaker doubted his access. This is a plausible expectation, given the widely held assumption in the published literature that young children fail to understand the 
Working understanding of knowledge sources

sources of their knowledge (e.g. Harris, 2002). Yet it turned out not to be the case at least with our procedure.

One interesting possibility is that results would be different for different kinds of knowledge. In our task, the Experimenter merely acted as a proxy for the child herself. Had the child experienced the same visual or tactile access to the target toy as the Experimenter, she would have gained the same knowledge. In contrast, for other kinds of knowledge, the child is heavily or entirely dependent on the trustworthiness or cooperativeness of another person. For example, when children learn a new name for an unfamiliar object, they have no way of discovering for themselves its reliability. The same is true when they are told about a past or future event remote from their own direct experience. On the one hand, the transparency of the knowing process in our tasks might make it less likely that children hold tentatively knowledge gained indirectly. On the other hand, children may be more trusting of knowledge gained from others when they learn conventional knowledge. Either way, there may be interesting and important differences in the developmental course of truth assessments of socially constructed knowledge, compared with knowledge which in principle at least can be checked against physical reality. More broadly, the source monitoring activity that children reveal in their confidence in knowledge gained from different sources, and possibly also in their explicit source reports, may vary for different knowledge domains.

The second basis of children's uncertainty in knowledge gained indirectly form others involved complex processes of source identification and evaluation. In line with the strong explanation, children saw the specific implications of the speaker's doubt about his or her own access: Children more frequently accepted that it could be the other toy when the Experimenter expressed doubt about his access than 
Working understanding of knowledge sources

when Mole expressed doubt about the toy's identity. Four- to 5-year-olds maintained this differentiation between Experimenter's and Mole's doubt after a delay, but 3 - to 4-year-olds did not.

We conclude that children aged between 3 and 5 years engage in increasingly sophisticated source monitoring activity, identifying the source of their knowledge and making appropriate evaluations of its reliability. In our task, as mentioned in the introduction, this involved taking into account the speaker's source of knowledge and making inferences from that about the likely truth of what the speaker told them. This is all the more impressive given that source monitoring was not triggered by an explicit question "How do you know...?" but merely by questions about knowledge content: "Which one is it?" or "Could it be the other one?" The exception to this sophisticated pattern of responding was the small sample of 3-year-olds in Experiment 1 (mean age 3;7), who showed over-confidence in knowledge gained from the speaker. Like the older children, these young ones nearly always denied that it could be the other toy when they had identified the toy for themselves, but unlike the older ones they did so no less frequently when they had been told the toy's identity. Of course, had these young children subsequently seen for themselves that the toy's property was not as the Experimenter said, they would have updated their belief appropriately (Robinson, Mitchell \& Nye, 1995). Older children, however, showed a more subtle understanding that knowledge gained from the Experimenter could have been false: They accepted the possibility of its falsity even in the absence of contradicting direct evidence. Note that our results do not allow the conclusion that this more subtle understanding is gained only at 4 years of age, since it was found in the nursery samples in Experiments 2 and 3 that included a mix of 3-and 4-year-olds. 
Working understanding of knowledge sources

The possibility was raised in the introduction that explicit understanding of sources of knowledge might be neither necessary nor sufficient for realising the significance of the speaker's doubt about his input. The findings of Experiment 1 provide no support for explicit understanding being insufficient: Children who responded correctly to the explicit source questions also tended to respond correctly to the doubt questions. However the results raise the possibility that explicit understanding of knowledge sources might not be necessary for appropriate uncertainty in knowledge gained from another person compared with knowledge gained directly: Some explicit source failers also showed such relative uncertainty. In this respect, children revealed working understanding of their knowledge sources without necessarily revealing verbally explicit understanding. When children are expected to comment explicitly on how they know, as in Experiment 1 and in classic theory of mind studies (e.g. Wimmer, Hogrefe \& Perner, 1988), or when children are asked to predict how they could find out (e.g. O’Neill, Astington and Flavell, 1992), limitations in their understanding are highlighted. In the doubt task in contrast, children focused on the identity of the toy in the tunnel. From the pattern of responses to the doubt and repeated identity questions, we the researchers drew inferences about children's access to source-specifying information and evaluation of their sources of knowledge. Examined in this indirect way, we found little fault with older 3- and 4year-olds' understanding. Their pattern of responding was broadly similar to that we would expect from adults in an age-appropriate task. A question for future research concerns the developmental relationship between these two levels of understanding: How do children come to reflect on sources of knowledge, and what advantages do they gain from such reflection? 
Working understanding of knowledge sources

\section{References}

Birch, S.A.J., \& Bloom, P (2002). Preschoolers are sensitive to the speaker's knowledge when learning proper names. Child Development, 73, 434-444.

Clements, W.A. \& Perner, J. (1994). Implicit understanding of belief. Cognitive Development, 9, 377-396.

Gopnik, A. \& Graf, P. (1988). Knowing how you know: Young children's ability to identify and remember the sources of their beliefs. Child Development, 59, 1366-1371.

Harris, P.L. (2002). Checking our sources: The origins of trust in testimony. Studies in the History and Philosophy of Science, 33, 315-333.

Johnson, M. K., Hashtroudi, S. \& Lindsay, S. D. (1993). Source monitoring. Psychological Bulletin, 114, 3-28.

Koenig, M. A., Clement, F. \& Harris, P. L. (2004). Trust in testimony: Children's use of true and false statements. Psychological Science, 15, 694-698.

Koenig, M.A. \& Harris, P.L. (2005). Preschoolers mistrust ignorant and inaccurate speakers. Child Development, 76, 1261-1277.

O’Neill, D. K., Astington, J. W. \& Flavell, J. H. (1992). Young children's understanding of the role that sensory experiences play in knowledge acquisition. Child Development, 63, 474-490.

O’Neill, D. K. \& Gopnik, A. (1991). Young children's ability to identify the sources of their beliefs. Developmental Psychology, 27, 390-397.

Perner, J. (1991). Understanding the Representational Mind. Cambridge, Mass.:MIT Press. 
Working understanding of knowledge sources

Pillow, B.H. \& Anderson, K.L. (2006) Children's awareness of their own certainty and understanding of deduction and guessing. British Journal of Developmental Psychology, 24, 823-849.

Robinson, E.J., Mitchell, P., \& Nye, R. (1995). Young children's treating of utterances as unreliable sources of knowledge. Journal of Child Language, 22, $663-685$.

Robinson, E. J. \& Whitcombe, E. L. (2003). Children's suggestibility in relation to their understanding about sources of knowledge. Child Development, 74, 4862.

Ruffman, T., Garnham,W., Import, A., \& Connolly, D. (2001). Does eye gaze indicate implicit knowledge of false belief? Charting transitions in knowledge. Journal of Experimental Child Psychology, 80, 201-224.

Sabbagh, M.A. \& Baldwin, D.A. (2001). Learning words from knowledgeable versus ignorant speakers: Links between preschoolers' theory of mind and semantic development. Child Development, 72, 1054-1070.

Whitcombe, E. L. \& Robinson, E. J. (2000). Children's decisions about what to believe and their ability to report the source of their belief. Cognitive Development, 15, 329-346.

Wimmer, H., Hogrefe, G. J. \& Perner, J. (1988). Children's understanding of informational access as source of knowledge. Child Development, 59, 386396. 
Working understanding of knowledge sources

Footnote 1.

In a preliminary study $(\mathrm{N}=87$ children aged between $3 ; 5$ and $4 ; 4$, mean age $4 ; 0)$ we checked that children were sensitive to the Experimenter's information access. Children were more likely to repeat the Experimenter's suggestion when he was well-informed (e.g. he had felt the toy to identify its hardness) and they were not (e.g. they had seen the toy), than when both child and Experimenter were poorly informed (e.g. both had seen the toy to identify its hardness). Children repeated the Experimenter's suggestion on a mean of 1.61 trials out of 2 (sd .60) when he was well informed, but on 1.23 trials $(.62)$ when both were guessing: $F(1,86)=$ 17.99, $\mathrm{p}<.001, \eta^{2}=1.71$ 
Table 1.

Procedure for Experiment 1.

\begin{tabular}{|c|c|c|}
\hline & Doubt Trials & Source Trials \\
\hline (i) & \multicolumn{2}{|c|}{ Properties of toys identified. One toy is hidden in the tunnel. } \\
\hline (ii) & \multicolumn{2}{|c|}{ Speaker feels (Tell trials) or looks (Direct trials). } \\
\hline & Speaker correctly identifies & Speaker correctly identifies \\
\hline & target on both Tell and & target on Tell trials but \\
\hline & Direct trials. & misidentifies on Direct trials. \\
\hline (iii) & \multicolumn{2}{|c|}{ Child sees (Tell trials) or looks (Direct trials). } \\
\hline (iv) & \multicolumn{2}{|c|}{ Child is asked, "Which one is inside, please?" } \\
\hline (v) & Doubt question: "I'm not & Source question: "Did you find \\
\hline & sure I felt / looked properly. & out it was the hard / soft one \\
\hline & Could it be the [other one]?" & because I told you, yes or no?" \\
\hline (vi) & \multicolumn{2}{|c|}{ Toy is removed from tunnel to check its identity. } \\
\hline
\end{tabular}


Working understanding of knowledge sources

Table 2

Experiment 2: Number of children changing their identity response on 0, 1, and 2 repeated identity questions (out of 2 ).

Number of changes to identity judgment

\begin{tabular}{llll} 
& 0 & 1 & 2 \\
\hline Experimenter & 19 & 4 & 1 \\
Monkey & 20 & 4 & 0 \\
\hline Total & 39 & 8 & 1 \\
\hline & Tell Trials & & \\
Experimenter & 10 & 12 & 2 \\
Monkey & 9 & 9 & 6 \\
\hline Tell & 19 & 21 & 8
\end{tabular}


Working understanding of knowledge sources

Table 3

Experiment 3: Frequency and percentage of "No" responses to the doubt question.

\begin{tabular}{|c|c|c|c|c|c|}
\hline & \multirow[t]{2}{*}{ Age group } & \multicolumn{2}{|c|}{ Mole doubt condition } & \multicolumn{2}{|c|}{ Experimenter doubt condition } \\
\hline & & Direct & Tell & Direct & Tell \\
\hline \multirow[t]{4}{*}{ No delay } & 3- to 4-years & $21 / 26$ & $15 / 26$ & $24 / 29$ & $7 / 29$ \\
\hline & & $81 \%$ & $58 \%$ & $83 \%$ & $24 \%$ \\
\hline & 4- to 5-years & $18 / 18$ & $11 / 18$ & $21 / 21$ & $6 / 21$ \\
\hline & & $100 \%$ & $61 \%$ & $100 \%$ & $29 \%$ \\
\hline \multirow[t]{4}{*}{ Delay } & 3- to 4-years & $16 / 23$ & $9 / 21$ & $20 / 28$ & $11 / 26$ \\
\hline & & $70 \%$ & $43 \%$ & $71 \%$ & $42 \%$ \\
\hline & 4- to 5-years & $14 / 15$ & $12 / 18$ & $17 / 20$ & $6 / 21$ \\
\hline & & $93 \%$ & $67 \%$ & $85 \%$ & $29 \%$ \\
\hline
\end{tabular}

